Article

\title{
Inguinal Ring RNA Sequencing Reveals Downregulation of Muscular Genes Related to Scrotal Hernia in Pigs
}

\author{
Gabrieli de Souza Romano ${ }^{1}$, Adriana Mercia Guaratini Ibelli ${ }^{2,3}{ }^{\circledR}$, William Raphael Lorenzetti ${ }^{4}$, \\ Tomás Weber ${ }^{5}$, Jane de Oliveira Peixoto ${ }^{2,3}{ }^{(0)}$, Mauricio Egídio Cantão ${ }^{2}$, \\ Marcos Antônio Zanella Mores ${ }^{2}$, Nelson Morés ${ }^{2}$, Victor Breno Pedrosa ${ }^{6}$ (D), \\ Luiz Lehmann Coutinho ${ }^{7}$ and Mônica Corrêa Ledur ${ }^{2,4, * \mathbb{D}}$ \\ 1 Programa de Pós-Graduação em Zootecnia, Universidade Federal da Bahia, Av. Adhemar de Barros, \\ 500-Ondina, Salvador 40170-110, Bahia, Brazil; gabisouza_romano@yahoo.com.br \\ 2 Embrapa Suínos e Aves, Concórdia, Rodovia BR-153, Km 110, Distrito de Tamanduá, 321, \\ Santa Catarina 89715-899, Brazil; adriana.ibelli@embrapa.br (A.M.G.I.); jane.peixoto@embrapa.br (J.d.O.P.); \\ mauricio.cantao@embrapa.br (M.E.C.); marcos.mores@embrapa.br (M.A.Z.M.); \\ nelson.mores@embrapa.br (N.M.) \\ 3 Programa de Pós-Graduação em Ciências Veterinárias, Universidade Estadual do Centro-Oeste, Alameda \\ Élio Antonio Dalla Vecchia, 838-Vila Carli, Guarapuava 85040-167, Paraná, Brazil \\ 4 Programa de Pós-Graduação em Zootecnia, UDESC-Oeste, Rua Beloni Trombeta Zanin 680E-Bairro Santo \\ Antônio, Chapecó 89815-630, SC, Brazil; williamlorenzetti20@hotmail.com \\ 5 BRF SA, Curitiba, PR. Present address: Instituto Federal de Educação, Ciência e Tecnologia do Rio Grande \\ do Sul, Rodovia RS-135, KM 25-Distrito Eng. Luiz, Sertão 99170-000, RS, Brazil; samotweber@hotmail.com \\ 6 Departamento de Zootecnia, Setor de Ciências Agrárias e Tecnologia, Universidade Estadual de Ponta \\ Grossa, Av. General Carlos Cavalcanti, 4748-Uvaranas, Ponta Grossa 84030-900, Paraná, Brazil; \\ vbpedrosa@uepg.br \\ 7 Departamento de Zootecnia, Escola Superior de Agricultura Luiz de Queiroz (ESALQ), Universidade de São \\ Paulo, ESALQ/USP, Av. Pádua Dias, 11, Piracicaba 13418-900, São Paulo, Brazil; llcoutinho@usp.br \\ * Correspondence: monica.ledur@udesc.br or monica.ledur@embrapa.br; Tel.: +55-49-3441-0411
}

Received: 12 December 2019; Accepted: 15 January 2020; Published: 21 January 2020

\begin{abstract}
Scrotal hernias (SH) are common congenital defects in commercial pigs, characterized by the presence of abdominal contents in the scrotal sac, leading to considerable production and animal welfare losses. Since the etiology of SH remains obscure, we aimed to identify the biological and genetic mechanisms involved in its occurrence through the whole transcriptome analysis of SH affected and unaffected pigs' inguinal rings. From the 22,452 genes annotated in the pig reference genome, 13,498 were expressed in the inguinal canal tissue. Of those, 703 genes were differentially expressed (DE, FDR < 0.05) between the two groups analyzed being, respectively, 209 genes upregulated and 494 downregulated in the SH-affected group. Thirty-seven significantly overrepresented GO terms related to $\mathrm{SH}$ were enriched, and the most relevant biological processes were muscular system, cell differentiation, sarcome reorganization, and myofibril assembly. The calcium signaling, hypertrophic cardiomyopathy, dilated cardiomyopathy, and cardiac muscle contraction were the major pathways possibly involved in the occurrence of the scrotal hernias. The expression profile of the DE genes was associated with the reduction of smooth muscle differentiation, followed by low calcium content in the cell, which could lead to a decreased apoptosis ratio and diminished muscle contraction of the inguinal canal region. We have demonstrated that genes involved with musculature are closely linked to the physiological imbalance predisposing to scrotal hernia. According to our study, the genes MYBPC1, BOK, SLC25A4, SLC8A3, DES, TPM2, MAP1CL3C, and FGF1 were considered strong candidates for future evaluation.
\end{abstract}

Keywords: transcriptome; congenital disease; differentially expressed genes 


\section{Introduction}

The average economic losses estimated globally in livestock due to animal health are over 20\% [1], and the congenital anomalies are significant causes of economic losses. Scrotal hernias are common congenital defects in pigs with frequencies ranging from $0.39 \%$ to $9.1 \%$ according to the animal breeds and lines [2,3]. This condition occurs when abdominal content is present in the scrotal sac, which affects the production, health and animal welfare, leading to economic losses $[4,5]$.

Anatomical factors, such as failure of involution of the inner inguinal ring, imbalance of collagen proportions, non-obliteration of the processus vaginalis, and low muscle contraction, can lead to scrotal hernia [6-10]. Despite the environmental influence, significant additive genetic variances were found for $\mathrm{SH}$ [3]. In addition, some studies have identified genomic regions and candidate genes associated with this defect [6,11-13]. Although these studies provided important information, the approaches used may have been insufficient to explain the etiology of this defect, since some phenotypes can be caused by differences in gene expression, and no variation in genomic sequences occurs [14].

In this perspective, we aimed to clarify the etiology of scrotal hernia by studying its transcriptional events. Gene expression studies allow a better understanding of metabolic and physiological knowledge of the hernia pathology through functional analysis. Thus, it is possible to associate several genes that influence scrotal hernia to pathways and genetic networks that act together in the biological regulation of this defect [15]. Therefore, this study aimed to identify genes and molecular mechanisms involved in the occurrence of scrotal hernia in pigs through the whole inguinal ring transcriptome analysis of normal and scrotal hernia-affected pigs.

\section{Material and Methods}

\subsection{Animals and Sample Collection}

A total of eight non-castrated Landrace male pigs, with 60 days of age, belonging to the same nucleus farm from a private company located in Santa Catarina State, Brazil, was used in this study. Animals were raised according to the technical recommendations for this line, receiving water and feed ad libitum. The pigs were characterized as normal and affected with scrotal hernia and then transported to the Embrapa Swine and Poultry National Research Center, located in Concórdia, SC, Brazil, for necropsy and sample collection. The euthanasia was carried out by electrocution for $10 \mathrm{~s}$ followed by immediate bleeding, according to the practices recommended by the Ethics Committee on Animal Utilization of the Embrapa Swine and Poultry National Research Center (protocol number 011/2014), which follows the international guidelines on animal welfare. Approximately $1 \mathrm{~cm}$ of the inguinal ring tissue was collected in circular form from four healthy and four scrotal hernia-affected pigs, immediately stored in liquid nitrogen, and frozen at $-80^{\circ} \mathrm{C}$ ) for subsequent gene expression analysis. The normal pigs were selected from families with no history of scrotal hernia at least in the last three generations.

\subsection{Total RNA Extraction, Library Preparation and Sequencing}

Approximately $100 \mathrm{mg}$ of the inguinal ring tissue was ground using liquid nitrogen and a mortar, mixed to $1 \mathrm{~mL}$ Trizol reagent (Invitrogen Life Technologies, Carlsbad, CA, USA) and incubated for $5 \mathrm{~min}$ in a room temperature (RT) and $0.2 \mathrm{~mL}$ chloroform were added. The tubes were shaken vigorously and centrifuged at $12,000 \times g$ for $15 \mathrm{~min}$ at $4{ }^{\circ} \mathrm{C}$. Approximately $600 \mu \mathrm{L}$ of the upper phase containing the RNA were transferred for a new microtube, where an equal volume of $70 \%$ ethanol was added. At this stage, the total RNA isolation was performed using the Qiagen RNeasy ${ }^{\circledR}$ Mini kit (Qiagen, Hilden, NRW, Germany), following the manufacturer's instructions. 
The total RNA samples were quantified using a Biodrop spectrophotometer (Biodrop, Cambridge, UK) and samples with an OD260:OD280 ratio greater than 1.9 were considered pure. The integrity was confirmed in 1.5\% agarose gel and also using an Agilent 2100 bioanalyzer (Agilent Technologies; Santa Clara, CA, USA). Samples with RIN > 8.0 were used for the RNA library preparation with a TruSeq Stranded mRNA Library Prep Kit (Illumina, Inc., San Diego CA, USA) using approximately $2 \mu \mathrm{g}$ of total RNA starting material, according to the manufacturer's recommendations. The size of the libraries was evaluated in a Agilent 2100 bioanalyzer (Agilent Technologies, Santa Clara, CA, USA) and quantified by qPCR. Sequencing was performed in an Illumina HiSeq 2500 (lllumina, San Diego CA, USA), producing paired-end sequences $(2 \times 100 \mathrm{bp})$ at the Functional Genomics Center, ESALQ, University of São Paulo, Piracicaba, São Paulo, Brazil.

\subsection{RNA-Sequencing Analyses}

For data quality control, low quality sequences (QPhred $<24)$, short sequences $(<70 \mathrm{bp}$ ), poly A/T tails, contaminants (phiX), and sequence adapters were removed using SeqyClean software (1.8.11, Ilya Zhbannikov, Durham, NC, USA) [16]. Then, sequences were mapped against the pig reference genome (SusScrofa 11.1, Ensembl 92) using the STAR [17] program (2.7, Alexander Dobin, Oyster Bay, NY, USA). The EdgeR [18] package was used to identify differentially expressed genes between the normal and scrotal hernia-affected pigs. Negative and positive $\log _{2}$ fold change (LogFC) indicate, respectively, downregulation and upregulation of genes in the affected compared to the normal group. The $p$-value was adjusted for multiple tests using the false discovery rate (FDR), according to Benjamini-Hochberg. Genes were declared as differentially expressed (DE) when FDR $<0.05$ and $\log \mathrm{FC}>0.5$.

\subsection{Functional Analysis}

The list of DE genes between the analyzed groups were submitted to a gene ontology analysis using the DAVID Bioinformatics Resources 6.8 database (accessed on 12 May 2019) [19] to obtain genes functionally related to biological processes and metabolic pathways (KEGG). The REVIGO resource was employed to summarize and visualize the enriched GO terms [20]. The analysis of the interaction among all the DE annotated genes was performed using the STRING database [21]. To determine the function of the transcripts that were specified as new genes, the blast2go software (5.2, BioBam Bioinformatics S.L,Valencia, Spain ) was used [22].

\section{5. $q P C R$ Confirmation}

The validation of the RNA-Seq results was performed using quantitative PCR (qPCR) of the same samples used in the RNA-Seq analysis. The complementary DNA (cDNA) synthesis was performed with the SuperScript III TM First-Strand Synthesis Supermix Kit (Invitrogen, Carlsbad, CA, USA) using $3 \mu \mathrm{g}$ of total RNA. Primers were designed in exon-exon junctions with the Primer-Blast online tool [23], using sequences obtained in the Genebank [24] and Ensembl [25] databases for eight selected genes: Myosin binding protein $C$ slow type (MYBPC1), desmin (DES), actin $\alpha 1$ skeletal muscle (ACTA1), actin $\gamma 2$ (ACTG2), microtubule associated protein 1 light chain $3 \gamma$ (MAP1LC3C), glucoronidase $\beta$ (GUSB), calponin 1 (CNN1), and fibroblast growth factor 1 (FGF1) (Table 1). These genes were selected based on the $\log F C, F D R$ and gene function. The primers quality was evaluated in the NetPrimer online software [26].

The qPCR reactions were performed in QuantStudio 6 (Applied Biosystems, San Francisco, CA, USA) equipment, in a final volume of $15 \mu \mathrm{L}$ containing $1 \times$ Maxima Mastermix SYBR Green (Fermentas, Waltham, MA, USA), $0.14 \mu \mathrm{M}$ for each primer and $2 \mu \mathrm{L}$ of diluted cDNA. The cycle threshold (Ct) means were collected and the relative quantification analysis was performed using the Relative Expression Software Tool 2009 (REST 2009) [27], which uses a pair wise fixed reallocation randomization test. The normalization was carried out using the PPIA (peptidyl-prolyl cis-trans omerase A) and RPL19 (ribosomal protein L19) reference genes, as described by Lorenzetti et al. [28]. Genes were considered DE when $p \leq 0.05$. 
Table 1. Primers used in the qPCR analysis of the inguinal ring tissue in pigs.

\begin{tabular}{|c|c|c|}
\hline Gene & Primer Sequence & Ensembl ID \\
\hline MYBPC1 & $\begin{array}{l}\text { F: CAAAAGGGGAGGCTGGAACT } \\
\text { R: GCCCGACTACTCAAACCTGG }\end{array}$ & ENSSSCG00000000866 \\
\hline$D E S$ & $\begin{array}{l}\text { F: ACTTCCGAGAAACAAGCCCT } \\
\text { R: TGGCTTTAGAGCACCTCGTG }\end{array}$ & ENSSSCG00000020785 \\
\hline ACTA1 & $\begin{array}{l}\text { F: TGAAGATCAAGATCATCGCCCC } \\
\text { R: CAGCTGTTGGAATGGGGTTTAG }\end{array}$ & ENSSSCG00000010190 \\
\hline ACTG2 & $\begin{array}{l}\text { F: CCTTCATCGGCATGGAGTCAG } \\
\text { R: CAGCTGTTGGAATGGGGTTTAG }\end{array}$ & ENSSSCG00000008294 \\
\hline MAP1LC3C & $\begin{array}{l}\text { F: TGGAAACAGCTGGAGGAATGAG } \\
\text { R: CСTCTCTTCTGGTTGCTAAGCTC }\end{array}$ & ENSSSCG00000010870 \\
\hline GUSB & $\begin{array}{l}\text { F: GACGGACACCTCCAAGTACC } \\
\text { R: CAGTCCCGCGTAGTTGAAGAA }\end{array}$ & ENSSSCG00000007739 \\
\hline CNN1 & $\begin{array}{l}\text { F: TGAGGTCAAGAACAAGCTGGC } \\
\text { R: GGGTGGACTCATTGACCTTCTTC }\end{array}$ & ENSSSCG00000013614 \\
\hline FGF1 & $\begin{array}{l}\text { F: CAGTGACAGCACAGAGCAGA } \\
\text { R: GGTGCTTTCGAGGCTGAAGA }\end{array}$ & ENSSSCG00000024954 \\
\hline
\end{tabular}

F: forward; R: reverse.

\section{Results}

\subsection{Sequencing and Mapping}

From the whole transcriptome sequencing of the inguinal ring tissue, an average of 28.10 million reads/sample (paired-end $2 \times 100 \mathrm{bp}$ ) was generated. Approximately 23.8 million reads/sample were maintained after data quality control. A mean of $97.23 \%$ of the reads was mapped to the swine reference genome (SusScrofa 11.1, Ensembl 92).

\subsection{Differential Gene Expression}

A total of 13,498 genes (Table S1) were expressed in the inguinal ring transcriptome, corresponding to $60.12 \%$ of the total genes in Sus Scrofa genome version 11.1. Before the differential expression analysis, a multi-dimensional scaling (MDS) analysis was performed using all the transcripts to visualize the profile of the studied groups, demonstrating an evident separation of samples collected between the normal and scrotal hernia-affected pigs (Figure S1).

In the differentially expressed (DE) analysis, it was possible to verify that 703 genes had different levels of expression (FDR < 0.05) between the normal and affected pigs, of which $494(70.27 \%)$ were downregulated and 209 (29.73\%) upregulated in the affected group (Table S2). The top ten up- and downregulated genes in pigs affected with scrotal hernia, according to the logFC (Table 2), were related to regulation of intracellular transport, development and differentiation of cells and muscle structure, and phagocytosis. 
Table 2. Top 10 downregulated and upregulated genes in pigs affected with scrotal hernia.

\begin{tabular}{lcccc}
\hline \multicolumn{5}{c}{ Downregulated Genes } \\
\hline Ensemb1 Gene ID & Gene Symbol & Description & LogFC & FDR \\
\hline ENSSSCG00000010190 & ACTA1 & Actin, $\alpha$ skeletal muscle & -13.41 & $4.80 \times 10^{-8}$ \\
ENSSSCG00000000866 & MYBPC1 & Myosin binding protein C, slow type & -13.28 & $2.95 \times 10^{-10}$ \\
ENSSSCG00000016157 & MYL1 & Myosin light chain 1/3, skeletal muscle isoform & -12.91 & $4.82 \times 10^{-8}$ \\
ENSSSCG00000032720 & SMPX & Small muscular protein & -12.25 & $4.94 \times 10^{-7}$ \\
ENSSSCG00000014324 & MYOT & Myotilin & -11.85 & $2.27 \times 10^{-7}$ \\
ENSSSCG00000031903 & TNNT3 & Troponin T, fast skeletal muscle & -11.61 & $1.28 \times 10^{-7}$ \\
ENSSSCG00000039710 & MYL2 & Myosin regulatory light chain 2, & -11.33 & $1.33 \times 10^{-8}$ \\
ENSSSCG00000013354 & CSRP3 & Ventricular/cardiac muscle isoform & -11.24 & $6.61 \times 10^{-7}$ \\
ENSSSCG00000011325 & MYL3 & Cysteine and glycine-rich protein 3 & -10.96 & $5.96 \times 10^{-8}$ \\
ENSSSCG00000029441 & MYH2 & Myosin light chain 3 & -10.78 & $1.59 \times 10^{-6}$ \\
\hline & & Myosin-2 & & \\
\hline Ensemb1 Gene ID & Gene Symbol & Upregulated Genes & $\mathbf{l o g F C}$ & FDR \\
\hline ENSSSCG00000029289 & & Description & 7.13 & $1.51 \times 10^{-23}$ \\
ENSSSCG00000034838 & MAP1LC3C & Microtubule associated protein 1 light chain 3 $\gamma$ & 6.72 & $1.96 \times 10^{-26}$ \\
ENSSSCG00000039102 & & Uncharacterized & 5.01 & $1.04 \times 10^{-7}$ \\
ENSSSCG00000036318 & & Uncharacterized & 4.70 & $4.15 \times 10^{-7}$ \\
ENSSSCG00000036983 & & Uncharacterized & 4.67 & $3.20 \times 10^{-6}$ \\
ENSSSCG00000039804 & COL26A1 & Uncharacterized & 4.55 & $6.71 \times 10^{-8}$ \\
ENSSSCG00000007678 & Collagen type XXVI $\alpha 1$ chain & 4.54 & $4.37 \times 10^{-10}$ \\
ENSSSCG00000038719 & Uncharacterized & 4.53 & $7.59 \times 10^{-7}$ \\
ENSSSCG00000036203 & & Uncharacterized & 4.44 & $2.62 \times 10^{-6}$ \\
ENSSSCG00000039111 & & Uncharacterized & 4.42 & $3.48 \times 10^{-8}$ \\
\hline & & & \\
\end{tabular}

In the qPCR analysis, five of the eight evaluated genes were DE (Table 3) between the normal and scrotal hernia-affected groups. Furthermore, all analyzed genes had the same expression pattern of those obtained in the RNA-Seq results.

Table 3. Relative expression between normal and scrotal hernia-affected pigs obtained in the RNA-Seq and qPCR studies.

\begin{tabular}{ccccc}
\hline & \multicolumn{2}{c}{ RNA-Seq } & \multicolumn{2}{c}{ qPCR } \\
\hline Gene & LogFC & FDR & LogFC & $p$-Value \\
\hline MYBPC1 & -13.28 & $2.95 \times 10^{-10}$ & -12.29 & 0.000 \\
ACTA1 & -13.41 & $4.80 \times 10^{-8}$ & -13.29 & 0.105 \\
ACTG2 & -5.95 & $9.12 \times 10^{-8}$ & -5.97 & 0.006 \\
CNN1 & -3.73 & $4.16 \times 10^{-8}$ & -3.68 & 0.023 \\
DES & -7.45 & $6.09 \times 10^{-14}$ & -7.38 & 0.005 \\
FGF1 & 1.91 & $3.74 \times 10^{-3}$ & 1.65 & 0.067 \\
GUSB & 1.00 & $1.58 \times 10^{-2}$ & 0.71 & 0.082 \\
MAP1LC3C & 6.72 & $1.96 \times 10^{-26}$ & 8.27 & 0.023 \\
\hline
\end{tabular}

\subsection{Functional Annotation and Pathway Analysis}

From the 703 DE genes, 684 were coding genes, the other 19 genes had the biotypes IG_C_gene, IG_V_gene, lincRNA, miRNA, miscRNA, pseudogene, and ribozyme. From the DE genes, $81(11.52 \%)$ were classified as uncharacterized genes. When the sequences of the uncharacterized genes were aligned with databases available in the blast2go (5.2, BioBam Bioinformatics S.L,Valencia, Spain), it was possible to verify that $98.9 \%$ of them had similarities with genes already annotated (Table 4 , Table S3). Those genes were related to calcium ion binding, muscle contraction, and immune system. 
Table 4. Top five downregulated and upregulated uncharacterized genes between normal and scrotal hernia-affected group according to the $\log _{2}$ FC. The information about alignment, gene description, sequence length (nucleotides), $e$-value, and similarity (sim mean) was obtained in blast2go software (5.2, BioBam Bioinformatics S.L,Valencia, Spain).

\begin{tabular}{|c|c|c|c|c|c|}
\hline Ensembl Gene ID & Description & Length & $e$-Value & Sim Mean & $\log \mathrm{FC}$ \\
\hline ENSSSCG00000035429 & Hemojuvelin isoform $\mathrm{X} 3$ & 1706 & $5.00 \times 10^{-119}$ & 96.77 & -9.70 \\
\hline ENSSSCG00000034015 & $\begin{array}{l}\text { Xin actin-binding repeat-containing protein } 1 \\
\text { isoform } \mathrm{X} 1\end{array}$ & 5511 & 0 & 87.7 & -9.49 \\
\hline ENSSSCG00000036235 & Creatine kinase M-type & 252 & $1.52 \times 10^{-17}$ & 100 & -8.78 \\
\hline ENSSSCG00000015747 & Myomesin-2 & 7217 & 0 & 93.38 & -7.76 \\
\hline ENSSSCG00000036052 & Titin isoform $\mathrm{X} 1$ & 1326 & 0 & 98.06 & -7.62 \\
\hline ENSSSCG00000039804 & Immunoglobulin heavy chain variable region & 405 & $1.29 \times 10^{-65}$ & 97.2 & 4.55 \\
\hline ENSSSCG00000036983 & IgG heavy chain precursor & 987 & 0 & 96.07 & 4.67 \\
\hline ENSSSCG00000036318 & IgG heavy chain precursor & 327 & $6.64 \times 10^{-73}$ & 98.62 & 4.70 \\
\hline ENSSSCG00000039102 & Immunoglobulin kappa Variable region & 297 & $5.24 \times 10^{-63}$ & 94.09 & 5.01 \\
\hline ENSSSCG00000029289 & Cystatin-9-like & 1146 & $1.71 \times 10^{-93}$ & 76.56 & 7.13 \\
\hline
\end{tabular}

The DE genes were grouped into 37 biological processes (BP), which were associated with five superclusters (Figure 1). From the most enriched GO terms, it was possible to highlight the BPs related to muscular system, including structural muscle development, muscle cell differentiation, sarcome reorganization, myofibril assembly, and ATP metabolic process. Considering the molecular function, it was possible to note the predominance of functions related to signaling, for example, calcium, the cell adhesion molecule, and structural constituent of muscle.

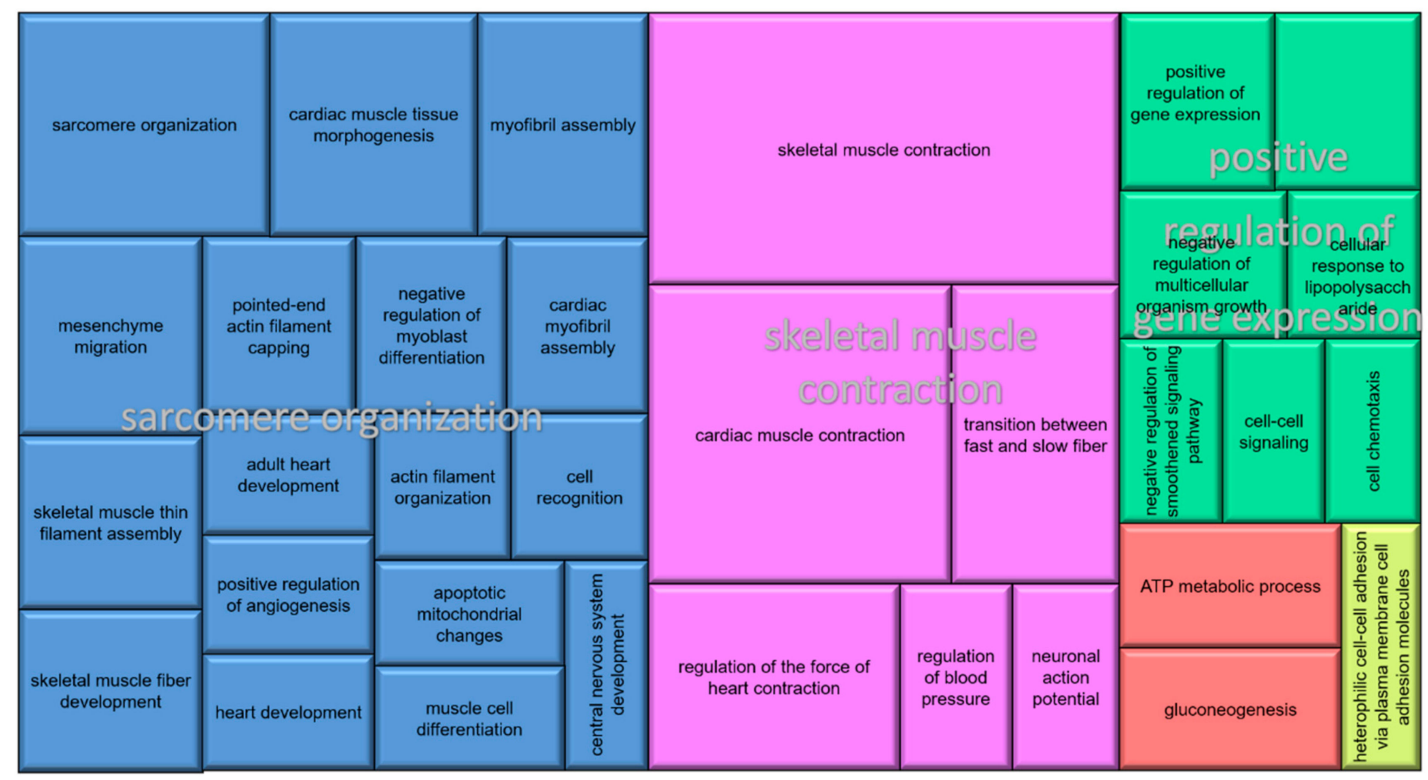

Figure 1. Superclusters of gene ontologies (GO) enriched with differentially expressed genes. Each color indicates a main GO term.

The gene network (Figure 2) grouped 31 nodes of major interactions, encompassing genes involved in ion transport, cGMP signaling, muscle contraction, and collagen metabolism. Most of the top DE genes (Table 1) were represented in the interacting gene network. Moreover, there is a link between enriched gene networks and pathways found in the DAVID database, which reinforces the possible influence of these genes in herniation processes (Table 5). 


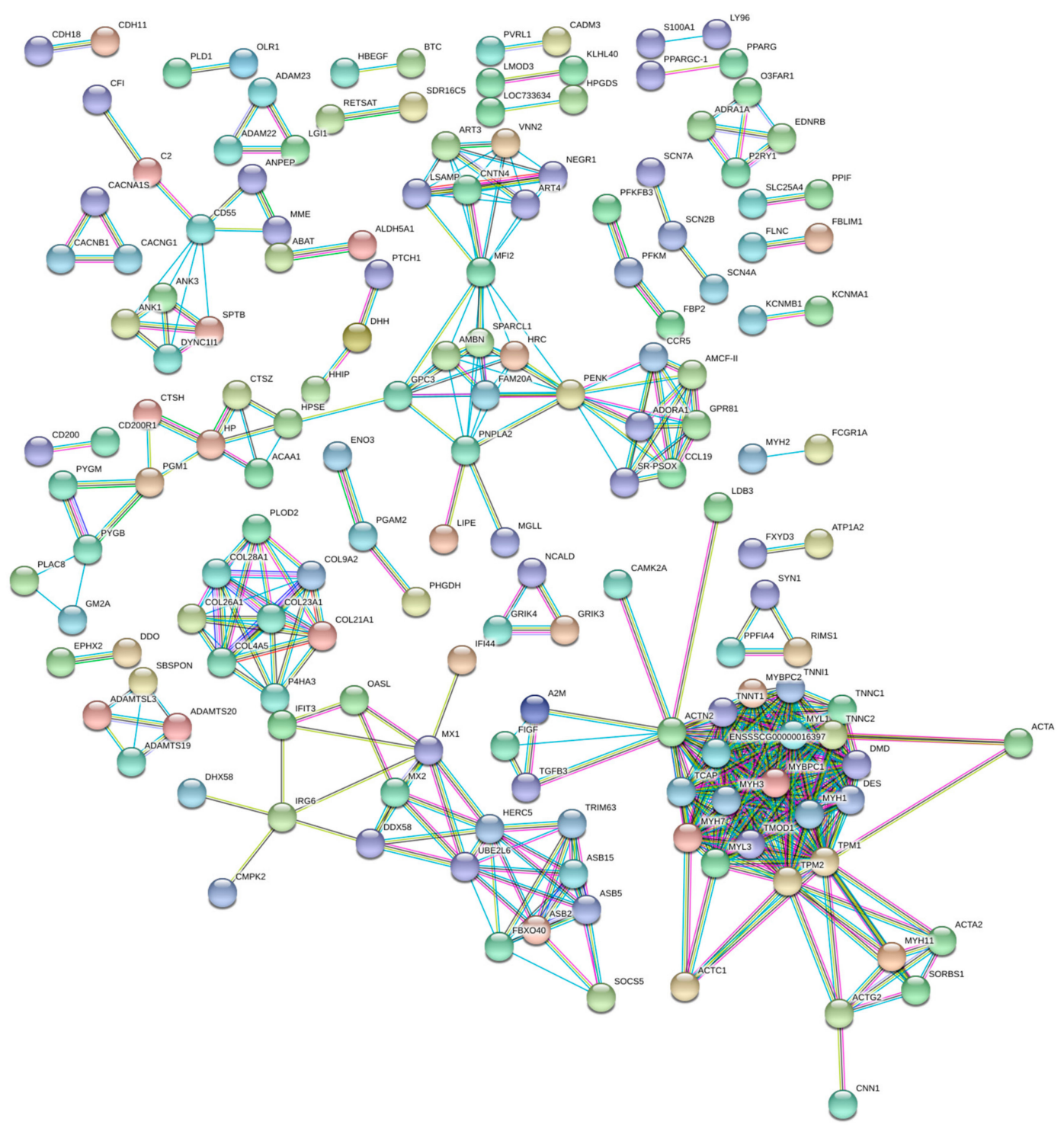

Figure 2. Gene network of DE genes in the inguinal ring tissue from normal and scrotal hernia-affected pigs using STRING. Colored circles represent genes and lines represent the predicted interactions between genes. 
Table 5. Canonical pathways of differentially expressed genes between normal and scrotal hernia-affected pigs.

\begin{tabular}{|c|c|c|c|}
\hline \multicolumn{2}{|c|}{ Canonical Pathway } & \multirow{2}{*}{$\begin{array}{c}\text { Genes } \\
\text { TGFB3; TPM1; ACTC1; TPM2; MYL3; TNNC1; } \\
\text { PRKAG3; CACNG1; CACNB1; SGCA; DES; CACNA1S }\end{array}$} & \multirow{2}{*}{$\frac{p \text {-Value }}{4.16 \times 10^{-6}}$} \\
\hline ssc05410 & $\begin{array}{c}\text { Hypertrophic } \\
\text { cardiomyopathy (HCM) }\end{array}$ & & \\
\hline ssc05414 & Dilated cardiomyopathy & $\begin{array}{c}\text { TGFB3; TPM1; ACTC1; TPM2; ADRB1; MYL3; } \\
\text { TNNC1; CACNG1; CACNB1; SGCA; DES; CACNA1S }\end{array}$ & $7.72 \times 10^{-6}$ \\
\hline ssc04261 & $\begin{array}{l}\text { Adrenergic signaling in } \\
\text { cardiomyocytes }\end{array}$ & $\begin{array}{c}\text { MYH7; TPM1; ACTC1; TPM2; ATP1A2; PLCB4; } \\
\text { ADRA1A; ADRB1; MYL3; TNNC1; SCN7A; CACNG1; } \\
\text { CACNB1; CACNA1S }\end{array}$ & $2.64 \times 10^{-5}$ \\
\hline ssc04022 & $\begin{array}{l}\text { cGMP-PKG signaling } \\
\text { pathway }\end{array}$ & $\begin{array}{c}\text { SLC8A3; ATP1A2; PLCB4; MYLK2; ATP2A1; EDNRB; } \\
\text { ADRA1A; PPIF; ADRB1; MYLK; SLC25A4; KCNMB1; } \\
\text { MRVI1; ADORA1; CACNA1S }\end{array}$ & $5.02 \times 10^{-5}$ \\
\hline ssc04260 & $\begin{array}{l}\text { Cardiac muscle } \\
\text { contraction }\end{array}$ & $\begin{array}{l}\text { MYH7; TPM1; ACTC1; TPM2; ATP1A2; MYL3; } \\
\text { TNNC1; CACNG1; CACNB1; CACNA1S }\end{array}$ & $9.46 \times 10^{-5}$ \\
\hline ssc04152 & $\begin{array}{l}\text { AMPK signaling } \\
\text { pathway }\end{array}$ & $\begin{array}{l}\text { LIPE; ADRA1A; FBP2; PFKFB3; PPARG; PRKAG3; } \\
\quad \text { PFKM; CPT1B; SLC2A4; LEPR; PPARGC1A }\end{array}$ & $8.12 \times 10^{-4}$ \\
\hline ssc04020 & $\begin{array}{l}\text { Calcium signaling } \\
\text { pathway }\end{array}$ & $\begin{array}{c}\text { SLC8A3; PLCB4; MYLK2; TNNC2; ATP2A1; EDNRB; } \\
\text { ADRA1A; PPIF; ADRB1; TNNC1; MYLK; } \\
\text { SLC25A4; CACNA1S }\end{array}$ & $2.04 \times 10^{-3}$ \\
\hline ssc00250 & $\begin{array}{l}\text { Alanine, aspartate and } \\
\text { glutamate metabolism }\end{array}$ & ALDH5A1; GPT2; DDO; ABAT; ASPA & $1.31 \times 10^{-2}$ \\
\hline ssc04923 & $\begin{array}{l}\text { Regulation of lipolysis in } \\
\text { adipocytes }\end{array}$ & $\begin{array}{c}\text { LIPE; ADRB1; ENSSSCG00000010992; PNPLA2; } \\
\text { ADORA1; MGL }\end{array}$ & $1.51 \times 10^{-2}$ \\
\hline ssc01100 & Metabolic pathways & $\begin{array}{l}\text { TST; PIK3C2G; ALDH5A1; ANPEP; FUT8; GPT2; } \\
\text { AK5; PGM1; GALNT12; AK1; PHGDH; AMPD1; } \\
\text { PLCB4; GUSB; ABAT; ST3GAL5; B3GNT2; LPIN1; } \\
\text { CMPK2; HPGDS; HPSE; EPHX2; GAL3ST1; FBP2; } \\
\text { ACAA1; PLD1; PNPLA2; PC; PYGM; CKMT2; } \\
\text { P4HA3; CYP27A1; ATP6V0A4; PGAM2; ASPA; ENO3; } \\
\text { PFKM; ; CKB; DGKG; PYGB; MGLL; ACSM5 }\end{array}$ & $1.81 \times 10^{-2}$ \\
\hline ssc04910 & $\begin{array}{l}\text { Insulin signaling } \\
\text { pathway }\end{array}$ & $\begin{array}{c}\text { LIPE; FBP2; PYGM; PRKAG3; PPP1R3A; PPP1R3B; } \\
\text { PYGB; SLC2A4; PPARGC1A }\end{array}$ & $1.93 \times 10^{-2}$ \\
\hline ssc01230 & $\begin{array}{l}\text { Biosynthesis of amino } \\
\text { acids }\end{array}$ & GPT2; PHGDH; PC; PGAM2; ENO3; PFKM & $1.98 \times 10^{-2}$ \\
\hline ssc04931 & Insulin resistance & $\begin{array}{c}\text { PYGM; PRKAG3; PPP1R3A; CPT1B; PPP1R3B; PYGB; } \\
\text { SLC2A4; PPARGC1A }\end{array}$ & $2.49 \times 10^{-2}$ \\
\hline ssc03320 & PPAR signaling pathway & $\begin{array}{c}\text { OLR1; ENSSSCG00000010992; ACAA1; PPARG; } \\
\text { CYP27A1;CPT1B }\end{array}$ & $2.85 \times 10^{-2}$ \\
\hline ssc04270 & $\begin{array}{l}\text { Vascular smooth muscle } \\
\text { contraction }\end{array}$ & $\begin{array}{c}\text { PLCB4; MYLK2; } A D R A 1 A ; A C T A 2 ; M Y L K ; K C N M B 1 ; \\
\text { MRVI1; CACNA1S }\end{array}$ & $2.95 \times 10^{-2}$ \\
\hline ssc04922 & $\begin{array}{l}\text { Glucagon signaling } \\
\text { pathway }\end{array}$ & $\begin{array}{c}\text { PLCB4; PYGM; PRKAG3; PGAM2; CPT1B; } \\
\text { PYGB; PPARGC1A }\end{array}$ & $3.51 \times 10^{-2}$ \\
\hline ssc04921 & $\begin{array}{l}\text { Oxytocin signaling } \\
\text { pathway }\end{array}$ & $\begin{array}{l}\text { PLCB4; MYLK2; MYLK; CAMK1G; PRKAG3; } \\
\text { CACNG1; CACNB1; KCNJ5; CACNA1S }\end{array}$ & $3.91 \times 10^{-2}$ \\
\hline ssc01200 & Carbon metabolism & GPT2; PHGDH; FBP2; PC; PGAM2; ENO3; PFKM & $4.90 \times 10^{-2}$ \\
\hline
\end{tabular}

\section{Discussion}

This is the first study that presents a comprehensive transcriptome analysis related to the occurrence of scrotal hernia in pigs using an advanced sequencing strategy. Other studies have pointed out chromosomal regions, candidate genes, and polymorphisms associated with this pathology. However, the genetic mechanisms involved in the etiology of scrotal hernias have not been fully elucidated [11,12,29]. It was possible to observe that the expression profile of several genes in the inguinal ring transcriptome found in this study could explain pathological alterations, such as reduced 
calcium content in the cell and the presence of smooth muscle, which have already been reported to be involved with scrotal hernia $[9,30]$.

Among the genes with the highest differential expression levels between the affected and normal groups, it is possible to highlight four new genes (Table 4) related to the immune system (ENSSSCG00000039804, ENSSSCG00000036983, ENSSSCG00000036318, and ENSSSCG00000039102), characterizing a possible inflammation in the inguinal ring/canal of the animals as a consequence of the hernia development. Clear evidence of inflammatory response in muscle structures of the internal inguinal ring in herniated humans has been previously described [31]. The inflammatory process could be seen as a response to the additional stress of myocytes, due to the steady compressive effect exerted by the abdominal viscera in the inguinal area [32]. In addition, the GUSB gene overexpression in animals with scrotal hernia may illustrate the presence of an inflammatory process in the inguinal canal. The GUSB gene synthesizes the enzyme $\beta$-glucuronidase, essential for the normal restructuring of the extracellular matrix [33]. Increased levels of extracellular $\beta$-glucuronidase have been reported in various inflammatory pathologies [34].

\subsection{Prevalence of Patent Processus Vaginalis}

The non-obliteration of the processus vaginalis is one of the main factors responsible for the pre-disposition of scrotal hernia and, for this, the apoptosis of the smooth muscle is required [9]. Several downregulated genes in the affected group have important functions in the extrinsic pathways of the cellular apoptosis process, particularly the genes: AATK (apoptosis-associated tyrosine kinase), BOK (BCL2-related ovarian killer), and SLC25A4 (solute carrier family 25 member 4) [35-39]. Although these genes have not yet been associated with hernias, the BAX gene, from the BCL2 family, has already been considered a candidate for the occurrence of scrotal hernia in pigs [13]. Moreover, the MAP1LC3C (microtubule-associated protein 1 light chain 3), one of the top 10 upregulated genes in the affected group, is involved in autophagous processes [40]. The autophagy process may inhibit the process of apoptosis [41]. Therefore, the deregulation of the previously mentioned genes in scrotal hernia-affected animals may decrease the apoptosis of the smooth muscle, making these animals more susceptible to scrotal hernia.

The obliteration of the processus vaginalis and the scrotal hernia are strongly related. The presence of myofibroblasts possibly reflects the attempt of apoptosis by smooth muscle, through cellular differentiation, consisting in an important role in the processus vaginalis obliteration [42]. Here, some downregulated genes in the affected group were related to cell differentiation in muscle tissue (Figure 1), such as MYH11 (myosin, heavy chain 11, smooth muscle), ACTA2 (actin, $\alpha 2$, smooth muscle, aorta) and CNN1 (calponin 1, basic, smooth muscle). Such genes have already been reported as expressed in intermediate stages of differentiation in smooth muscle cells $[43,44]$. The lower expression of these genes in affected than in normal pigs suggests a reduction in the smooth muscle differentiation and, consequently, failure in the processus vaginalis obliteration, resulting in the development of scrotal hernia.

A significant metabolic pathway found in the transcriptome related to scrotal hernia in pigs was the calcium signaling pathway. Considering only studies with scrotal hernias, there is no previous research reporting genes involved in this signaling pathway. However, decreased calcium levels have been observed in tissues of herniated pigs when compared to normal tissues [30]. The role of ions calcium $\left(\mathrm{Ca}^{2+}\right)$ in the intrinsic pathways of apoptosis signaling has been extensively investigated. There is evidence that the reduction of ions $\mathrm{Ca}^{2+}$ in cells limit the activation of apoptosis [45]. In the present study, genes possibly involved in the apoptotic process, such as SLC8A3 (solute carrier family 8-member A3), ATP2A1 (ATPase sarcoplasmic/endoplasmic reticulum $\mathrm{Ca}^{2+}$ transporting 1), PLN (phospholamban), ADRB1 (adrenoceptor $\beta$ 1), CACNA1S (calcium voltage-gated channel subunit $\alpha 1 \mathrm{~S}$ ), and $E D N R B$ (endothelin receptor type B) were downregulated in scrotal hernia-affected pigs. The low expression of $A D R B 1, C A C N A 1 S$, and $E D N R B$, which mediate the entry of ions $\mathrm{Ca}^{2+}$ to the intracellular medium, suggests low $\mathrm{Ca}^{2+}$ stocks in the cytoplasm, consequently, reflects in the decrease of calcium in the mitochondria $[30,46]$. It is known that the absorption of $\mathrm{Ca}^{2+}$ into the mitochondria 
is crucial in triggering apoptotic signals [47]. In our study, the downregulation of the SLC8A3 gene, which encodes a mitochondrial $\mathrm{Na}^{2+} / \mathrm{Ca}^{2+}$ exchange protein [48], was observed. The disturbance of the mitochondrial permeability could prevent the release of cytochrome $\mathrm{c}$ into the cytoplasm making apoptosis impossible [9]. This result suggests that the decrease of intracellular and mitochondrial calcium can inhibit the programmed cell death of the smooth muscle cells during the processus vaginalis of pigs affected with scrotal hernias.

\subsection{Low Muscle Contractile Function in the Inguinal Region}

Abrahamson [7] proposed that the presence of a patent processus vaginalis does not necessarily indicate the development of an inguinal hernia. Other reasons that can cause the development of scrotal hernia were associated with the obturator and sphincter mechanism, described by Nyhus et al. [49], where the obturator mechanism is needed for the contraction of internal oblique and transverse abdominal muscles for inguinal ring closure, preventing the descent of abdominal contents into the scrotum. On the other hand, when the sphincter mechanism occurs, the contraction is just in the transverse abdominal muscle, resulting in the narrowing of the inguinal ring. In this context, muscle contraction is indispensable, and the committed calcium homeostasis may compromise this metabolic function [50], increasing the susceptibility of pigs to be affected with scrotal hernia.

Additionally, in our study, several muscle genes were DE in the inguinal transcriptome. The gene with the lowest expression in herniated animals, $M Y B P C 1$, is a crucial component of the sarcomere and important regulator of muscle function [51,52]. Furthermore, interactions of $M Y B P C 1$ with other negatively-regulated genes were observed in pigs affected with scrotal hernia (Figure 2), grouped into metabolic pathways and biological processes responsible for muscle contraction, such as ACTN2 ( $\alpha$-actinin-2), DES (desmin), MYL1 (myosin light chain 1/3 skeletal muscle isoform), MYL3 (myosin light chain 3), TMOD1 (tropomodulin 1), TNNC1 (troponin C slow skeletal and cardiac muscles), TNNI1 (troponin I slow skeletal muscle), TNNT1 (troponin T slow skeletal muscle), TPM2 (tropomyosin $2(\beta)$ ), ACTA1 (actin, $\alpha 1$, skeletal muscle), and ACTG2 (actin, $\gamma 2$, smooth muscle, enteric). The proteins encoded by these genes contribute together to the functioning of the muscle contractile machinery [53]. The lower expression of these muscle genes in affected pigs and, consequently, the lower muscle contraction may limit the obturator and sphincter mechanism, predisposing the animals to the development of scrotal hernia.

In this study, some enriched pathways were associated to cardiomyopathy (Table 5), being the first time that these pathways were related to scrotal hernias in pigs. In humans, it has been found that individuals with inguinal hernias also have a predisposition to cardiomyopathies. Therefore, it has been suggested that the etiology of these pathologies could be related, occurring due to the weakness of the connective tissue [54]. Some of the genes that were previously reported to be involved in both pathologies and associated with muscle contraction (ACTC1, DES, TNNC1, TPM1, TPM2, MYL3) were $\mathrm{DE}$ in our study. Some of those genes have a compensatory response to low contractile function, which may lead to hypertrophic and dilated cardiomyopathy, resulting in myocyte hypertrophy $[55,56]$. Moreover, the content of embryonic cardiac muscle in the gubernaculum during testicular descent has also been previously reported [57]. Thus, it is suggested that the low expression of the genes associated with cardiac muscle contraction present in the gubernaculum will allow myocyte hypertrophy and, consequently, an increase in the size of this structure, which may enlarge the inguinal ring in a non-physiological way and remain open after the testicular descent.

\subsection{Changes in Collagen Proportions in the Inguinal Ring}

Pathological changes in collagen are also involved in the development of scrotal hernia [58], resulting in weakness of the inguino-abdominal region [59]. In our study, several collagen family genes were DE: six genes were downregulated (COL23A1, COL28A1, COL4A5, ENSSSCG00000001500, and ENSSSCG00000023322) and two genes were upregulated (COL8A2 and COL26A1) in scrotal hernia-affected pigs. Lower expression of the COL23A1 gene may cause decreased protein expression 
of cell adhesion complex proteins, such as integrin [60], making the inguinal ring flexible. Furthermore, COL23A1 has already been associated to the development of scrotal hernia in pigs [11]. An important paralog of the ENSSSCG00000023322 gene, the COL9A1, has also been described as a potential candidate for scrotal hernia development in pigs [5]. Additionally, the upregulation of the COL26A1 gene was observed. This gene is involved in the initial development of testis and ovaries as an extracellular matrix component [61]. After birth, the high expression of COL26A1 may indicate an abnormal dynamic of the remodeling/degradation of the extracellular matrix. These results suggest that the deregulated expression of these collagen family genes in the affected animals may alter the collagen ratio, decreasing the collagen structures in the inguinal tissue, making it more easily degradable. Moreover, it is possible that there would be a decrease in the resistance and increase in the flexibility of the inguinal tissue, favoring the appearance of scrotal hernia.

Although several members of the collagen family were DE, no pathway in the functional analysis described the mechanisms involved in collagen metabolism. Therefore, we investigated a list of DE genes that may be related to the synthesis of this protein and identified genes potentially associated with this condition, such as HOXC10. The HOX family genes (homeobox) participate in collagen metabolism and are possibly related to the inguinal wall fragility. In this study, HOXC10 was downregulated in animals affected with scrotal hernia and, although it has not yet been associated with hernias, the HOXA10 gene, which belongs to the same gene family, has already been considered a candidate for causing this pathology [12].

In addition, it was possible to verify the upregulation of the FGF1 gene (fibroblast growth factor 1) in herniated animals. There is an evidence that the FGF1 gene can promote fibroblast proliferation [62]. Tanyel et al. [63] reported the presence of cells morphologically similar to fibroblasts associated with inguinal hernia. Moreover, the FGF1 gene can inhibit the differentiation of myofibroblasts induced by TGF- $\beta 1$, regulate the expression of type I collagen, and regulate collagenase-1 [64]. The type I collagen is predominantly found in connective tissues, and is mainly responsible for the tensile strength [10]. Thus, the over-expression of the FGF1 gene may alter the metabolism of type I collagen, making the inguinal region more flexible promoting the development of scrotal hernia.

The embryonic and fetal development comprises a complex series of well-orchestrated events and when properly performed result in a healthy newborn [65]. According to the results of our study, calcium signaling, hypertrophic cardiomyopathy, dilated cardiomyopathy, and cardiac muscle contraction were the major pathways possibly involved in the occurrence of the scrotal hernia phenotype. Therefore, the possible disproportion of the collagen in the inguinal tissue, the non-obliteration of the processus vaginalis, as well as the low contraction of the inguinal region predispose the animals to this anomaly. The functional analyses of the DE genes obtained in this study are in agreement with the events reported in the literature involved with scrotal hernia. It is important to note that the scrotal hernia was already present when the transcriptome was investigated. Therefore, some of the DE genes identified in our study could be more related to the consequence than to the cause of this anomaly. This study pointed out important molecular mechanisms, which contribute to the better understanding of scrotal hernias etiology in pigs. Further investigation is needed to confirm which of the DE genes are probably causing this process.

\section{Conclusions}

In this study, genes related to smooth muscle differentiation, calcium signaling pathways, and apoptosis were DE between normal and scrotal hernia-affected pigs. The expression profile of those genes in affected pigs was associated with the diminished smooth muscle differentiation, followed by low calcium content in the cell, leading to a reduced apoptosis ratio and muscle contraction of the inguinal canal region. We have demonstrated that genes involved with musculature are closely linked to the physiological imbalance predisposing animals to scrotal hernia. According to our study, the MYBPC1, BOK, SLC25A4, SLC8A3, DES, TPM2, MAP1CL3C, and FGF1 genes were considered strong candidates for future evaluation. 
Supplementary Materials: The following are available online at http://www.mdpi.com/2073-4425/11/2/117/s1, Figure S1: Multi-dimensional scaling (MDS) plot of control (HE06, HE08, HE16, HE18) in blue and scrotal hernia-affected samples (HE09, HE13, HE17, HE19) in red, based on the inguinal tissue transcriptome, Table S1: List of total genes that were identified in the inguinal ring transcriptome of scrotal hernia-affected and healthy pigs,

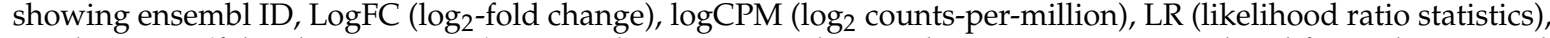
$p$-value, FDR (false discovery rate), name, description and type, chromosome, start and end for each gene and average CPM for normal and affected groups, Table S2: List of expressed values of all the differentially expressed genes between scrotal hernia-affected and healthy pigs, showing ensembl ID, LogFC ( $\log _{2}$-fold change), $\log C \mathrm{PM}$ ( $\log _{2}$ counts-per-million), LR (likelihood ratio statistics), $p$-value, FDR (false discovery rate), name, description and type, Chromosome, and start and end for each downregulated and upregulated gene, Table S3: List of manually annotated novel genes using the blast2go software, followed by its description, sequence length in bp, $e$-value, similarity (sim mean) and $\log _{2}$-fold change (logFC).

Author Contributions: Conceptualization: A.M.G.I., M.E.C., M.C.L., J.d.O.P., N.M., and T.W.; methodology: A.M.G.I., M.E.C., M.C.L., L.L.C., and J.O.P.; software: A.M.G.I. and M.E.C.; validation: G.d.S.R., A.M.G.I., M.E.C., M.C.L., and J.O.P.; formal analysis: G.S.R., A.M.G.I., M.E.C., M.C.L., and J.O.P.; investigation: G.S.R., W.R.L., A.M.G.I., M.E.C., M.C.L., and J.O.P.; resources: G.S.R., T.W., A.M.G.I., M.C.L., M.A.Z.M., W.R.L., and J.O.P.; data curation: G.S.R., A.M.G.I., M.E.C., M.C.L., and J.O.P.; writing-original draft preparation: G.S.R., J.O.P., M.C.L., V.B.P., and A.M.G.I.; writing-review and editing: G.S.R., T.W., M.C.L., W.R.L., V.B.P., J.O.P., A.M.G.I., M.E.C., M.A.Z.M., L.L.C., and N.M.; visualization: G.S.R., A.M.G.I., M.E.C., M.C.L., and J.O.P.; supervision: M.C.L.; project administration: M.C.L., J.O.P., A.M.G.I., and M.E.C.; funding acquisition: M.C.L. All authors have read and agreed to the published version of the manuscript.

Funding: This study was financed by the National Council for Scientific and Technological Development (CNPq), from the Brazilian Government, under process number 476146/2013-5.

Acknowledgments: The authors are grateful to A.L. Tessmann for technical assistance. G.S.R. received a scholarship from Research Support Foundation of the State of Bahia (FAPESB). W.R.L. was sponsored by a PROMOP/Udesc scholarship. This study was financed in part by the Coordenação de Aperfeiçoamento de Pessoal de Nível Superior-Brasil (CAPES) (finance code 001). M.C.L. and L.L.C. are CNPq fellows.

Conflicts of Interest: The authors declare no conflict of interest.

Availability of Data and Material: The datasets used or analyzed during the current study are available from the corresponding author on reasonable request. The transcriptome sequences are available in the SRA database with BioProject number PRJNA350530 and biosample numbers SAMN05941818, SAMN05941817, SAMN05941816, SAMN05941815, SAMN05941814, SAMN05941813, SAMN05941812, and SAMN05941811.

\section{References}

1. Derner, J.D.; Hunt, L.; Filho, K.E.; Ritten, J.; Capper, J.; Han, G. Livestock Production Systems; Springer: Berlin, Germany, 2017; pp. 347-372.

2. Mattsson, P. Prevalence of Congenital Defects in Swedish Hampshire, Landrace and Yorkshire Pig Breeds and Opinions on Their Prevalence in Swedish Commercial Herds. Master's Thesis, Swedish University of Agricultural Sciences, Uppsala, Sweden, 2011.

3. Sevillano, C.A.; Lopes, M.S.; Harlizius, B.; Hanenberg, E.H.A.T.; Knol, E.F.; Bastiaansen, J.W.M. Genome-wide association study using deregressed breeding values for cryptorchidism and scrotal/inguinal hernia in two pig lines. Genet. Sel. Evol. 2015, 47, 18. [CrossRef] [PubMed]

4. Elansary, M.; Stinckens, A.; Ahariz, N.; Cambisano, N.; Coppieters, W.; Grindflek, E.; van Son, M.; Buys, N.; Georges, M. On the use of the transmission disequilibrium test to detect pseudo-autosomal variants affecting traits with sex-limited expression. Anim. Genet. 2015, 46, 395-402. [CrossRef] [PubMed]

5. Grindflek, E.; Moe, M.; Taubert, H.; Simianer, H.; Lien, S.; Moen, T. Genome-wide linkage analysis of inguinal hernia in pigs using affected sib pairs. BMC Genet. 2006, 7, 25. [CrossRef] [PubMed]

6. Beck, J.; Bornemann-Kolatzki, K.; Knorr, C.; Taeubert, H.; Brenig, B. Molecular characterization and exclusion of porcine GUSB as a candidate gene for congenital hernia inguinalis/scrotalis. BMC Vet. Res. 2006, 2, 14. [CrossRef]

7. Abrahamson, J. Etiology and pathophysiology of primary and recurrent groin hernia formation. Surg. Clin. N. Am. 1998, 78, 953-972. [CrossRef]

8. Öberg, S.; Andresen, K.; Rosenberg, J. Etiology of Inguinal Hernias: A Comprehensive Review. Front. Surg. 2017, 4, 52. [CrossRef]

9. Tanyel, F.C. Obliteration of processus vaginalis: Aberrations in the regulatory mechanism result in an inguinal hernia, hydrocele or undescended testis. Turk. J. Pediatr. 2004, 46, 18-27. 
10. Rosch, R.; Junge, K.; Lynen, P.; Mertens, P.R.; Klinge, U.; Schumpelick, V. Hernia-A Collagen Disease? Eur. Surg. Acta Chir. Austriaca 2003, 35, 11-15. [CrossRef]

11. Du, Z.Q.; Zhao, X.; Vukasinovic, N.; Rodriguez, F.; Clutter, A.C.; Rothschild, M.F. Association and haplotype analyses of positional candidate genes in five genomic regions linked to scrotal hernia in commercial pig lines. PLoS ONE 2009, 4, e4837. [CrossRef]

12. Zhao, X.; Du, Z.; Vukasinovic, N.; Rodriguez, F.; Clutter, A.C.; Rothschild, M.F. Association of HOXA10, ZFPM2, and MMP2 genes with scrotal hernias evaluated via biological candidate gene analyses in pigs. Am. J. Vet. Res. 2009, 70, 1006-1012. [CrossRef]

13. Manalaysay, J.G.; Antonio, N.D.; Apilado, R.L.R.; Bambico, J.F.; Mingala, C.N. Screening of BCL-2 associated $\mathrm{X}$ protein gene polymorphism associated with scrotal hernia in domesticated swine using polymerase chain reaction-restriction fragment length polymorphism. Asian-Australas. J. Anim. Sci. 2017, 30, 262-266. [CrossRef]

14. Cookson, W.; Liang, L.; Abecasis, G.; Moffatt, M.; Lathrop, M. Mapping complex disease traits with global gene expression. Nat. Rev. Genet. 2009, 10, 184-194. [CrossRef] [PubMed]

15. Te Pas, M.; Madsen, O.; Calus, M.; Smits, M. The Importance of Endophenotypes to Evaluate the Relationship between Genotype and External Phenotype. Int. J. Mol. Sci. 2017, 18, 472. [CrossRef] [PubMed]

16. Zhbannikov, I.Y.; Arbeev, K.G.; Yashin, A.I. rqt: An R package for gene-level meta-analysis. Bioinformatics 2017, 33, 3129-3130. [CrossRef] [PubMed]

17. Dobin, A.; Davis, C.A.; Schlesinger, F.; Drenkow, J.; Zaleski, C.; Jha, S.; Batut, P.; Chaisson, M.; Gingeras, T.R. STAR: Ultrafast universal RNA-seq aligner. Bioinformatics 2013, 29, 15-21. [CrossRef] [PubMed]

18. Robinson, M.D.; McCarthy, D.J.; Smyth, G.K. edgeR: A Bioconductor package for differential expression analysis of digital gene expression data. Bioinformatics 2009, 26, 139-140. [CrossRef]

19. Huang, D.W.; Sherman, B.T.; Lempicki, R.A. Systematic and integrative analysis of large gene lists using DAVID bioinformatics resources. Nat. Protoc. 2009, 4, 44-57. [CrossRef]

20. Supek, F.; Bošnjak, M.; Škunca, N.; Šmuc, T. Revigo summarizes and visualizes long lists of gene ontology terms. PLoS ONE 2011, 6, e21800. [CrossRef]

21. Szklarczyk, D.; Franceschini, A.; Wyder, S.; Forslund, K.; Heller, D.; Huerta-Cepas, J.; Simonovic, M.; Roth, A.; Santos, A.; Tsafou, K.P.; et al. STRING v10: Protein-protein interaction networks, integrated over the tree of life. Nucleic Acids Res. 2015, 43, D447-D452. [CrossRef]

22. Götz, S.; García-Gómez, J.M.; Terol, J.; Williams, T.D.; Nagaraj, S.H.; Nueda, M.J.; Robles, M.; Talón, M.; Dopazo, J.; Conesa, A. High-throughput functional annotation and data mining with the Blast2GO suite. Nucleic Acids Res. 2008, 36, 3420-3435. [CrossRef]

23. Ye, J.; Coulouris, G.; Zaretskaya, I.; Cutcutache, I.; Rozen, S.; Madden, T.L. Primer-BLAST: A tool to design target-specific primers for polymerase chain reaction. BMC Bioinform. 2012, 13, 134. [CrossRef] [PubMed]

24. Sayers, E.W.; Cavanaugh, M.; Clark, K.; Ostell, J.; Pruitt, K.D.; Karsch-Mizrachi, I. GenBank. Nucleic Acids Res. 2019, 47, D94-D99. [CrossRef] [PubMed]

25. Zerbino, D.R.; Achuthan, P.; Akanni, W.; Amode, M.R.; Barrell, D.; Bhai, J.; Billis, K.; Cummins, C.; Gall, A.; Girón, C.G.; et al. Ensembl 2018. Nucleic Acids Res. 2018, 46, D754-D761. [CrossRef] [PubMed]

26. Biosoft, P. NetPrimer. Available online: http://www.premierbiosoft.com/netprimer/index.html (accessed on 3 April 2019).

27. Pfaffl, M.W. Relative expression software tool (REST(C)) for group-wise comparison and statistical analysis of relative expression results in real-time PCR. Nucleic Acids Res. 2002, 30, e36. [CrossRef]

28. Lorenzetti, W.R.; Ibelli, A.M.G.; De Oliveira Peixoto, J.; Mores, M.A.Z.; Savoldi, I.R.; Do Carmo, K.B.; De Oliveira, H.C.; Ledur, M.C. Identification of endogenous normalizing genes for expression studies in inguinal ring tissue for scrotal hernias in pigs. PLoS ONE 2018, 13, e0204348. [CrossRef]

29. Ding, N.S.; Mao, H.R.; Guo, Y.M.; Ren, J.; Xiao, S.J.; Wu, G.Z.; Shen, H.Q.; Wu, L.H.; Ruan, G.F.; Brenig, B.; et al. A genome-wide scan reveals candidate susceptibility loci for pig hernias in an intercross between White Duroc and Erhualian. J. Anim. Sci. 2009, 87, 2469-2474. [CrossRef]

30. Beuermann, C.; Beck, J.; Schmelz, U.; Dunkelberg, H.; Schütz, E.; Brenig, B.; Knorr, C. Tissue Calcium Content in Piglets with Inguinal or Scrotal Hernias or Cryptorchidism. J. Comp. Pathol. 2009, 140, 182-186. [CrossRef]

31. Amato, G.; Agrusa, A.; Romano, G.; Salamone, G.; Cocorullo, G.; Mularo, S.A.; Marasa, S.; Gulotta, G. Histological findings in direct inguinal hernia. Hernia 2013, 17, 757-763. [CrossRef] 
32. Amato, G.; Agrusa, A.; Romano, G.; Salamone, G.; Gulotta, G.; Silvestri, F.; Bussani, R. Muscle degeneration in inguinal hernia specimens. Hernia 2012, 16, 327-331. [CrossRef]

33. Antunes, I.F.; Haisma, H.J.; Elsinga, P.H.; Van Waarde, A.; Willemsen, A.T.M.; Dierckx, R.A.; De Vries, E.F.J. In vivo evaluation of 1-O-(4-(2-fluoroethyl-carbamoyloxymethyl)-2-nitrophenyl)-O- $\beta$-D-glucopyronuronate: A positron emission tomographic tracer for imaging $\beta$-Glucuronidase activity in a tumor/inflammation rodent model. Mol. Imaging 2012, 11,77-87. [CrossRef]

34. Naz, H.; Islam, A.; Waheed, A.; Sly, W.S.; Ahmad, F.; Hassan, M.I. Human $\beta$-Glucuronidase: Structure, Function, and Application in Enzyme Replacement Therapy. Rejuvenation Res. 2013, 16, 352-363. [CrossRef]

35. Bauer, M.K.A.; Schubert, A.; Rocks, O.; Grimm, S. Adenine nucleotide translocase-1, a component of the permeability transition pore, can dominantly induce apoptosis. J. Cell Biol. 1999, 147, 1493-1501. [CrossRef] [PubMed]

36. Czabotar, P.E.; Lessene, G.; Strasser, A.; Adams, J.M. Control of apoptosis by the BCL-2 protein family: Implications for physiology and therapy. Nat. Rev. Mol. Cell Biol. 2013, 15, 49-63. [CrossRef] [PubMed]

37. Honma, N.; Asada, A.; Takeshita, S.; Enomoto, M.; Yamakawa, E.; Tsutsumi, K.; Saito, T.; Satoh, T.; Itoh, H.; Kaziro, Y.; et al. Apoptosis-associated tyrosine kinase is a Cdk5 activator p35 binding protein. Biochem. Biophys. Res. Commun. 2003, 310, 398-404. [CrossRef]

38. Ma, S.; Rubin, B.P. Apoptosis-Associated tyrosine kinase 1 inhibits growth and migration and promotes apoptosis in melanoma. Lab. Investig. 2014, 94, 430-438. [CrossRef] [PubMed]

39. Zeng, L.; Li, T.; Xu, D.C.; Liu, J.; Mao, G.; Cui, M.-Z.; Fu, X.; Xu, X. Death receptor 6 induces apoptosis not through type I or type II pathways, but via a unique mitochondria-dependent pathway by interacting with Bax protein. J. Biol. Chem. 2012, 287, 29125-29133. [CrossRef] [PubMed]

40. Shpilka, T.; Weidberg, H.; Pietrokovski, S.; Elazar, Z. Atg8: An autophagy-related ubiquitin-like protein family. Genome Biol. 2011, 12, 226. [CrossRef]

41. Thorburn, A. Apoptosis and autophagy: Regulatory connections between two supposedly different processes. Apoptosis 2008, 13, 1-9. [CrossRef]

42. Hosgor, M.; Karaca, I.; Ozer, E.; Erdag, G.; Ulukus, C.; Fescekoglu, O.; Aikawa, M. The role of smooth muscle cell differentiation in the mechanism of obliteration of processus vaginalis. J. Pediatr. Surg. 2004, 39, 1018-1023. [CrossRef]

43. Kurpinski, K.; Lam, H.; Chu, J.; Wang, A.; Kim, A.; Tsay, E.; Agrawal, S.; Schaffer, D.V.; Li, S. Transforming growth factor- $\beta$ and notch signaling mediate stem cell differentiation into smooth muscle cells. Stem Cells 2010, 28, 734-742. [CrossRef]

44. Miano, J.M.; Cserjesi, P.; Ligon, K.L.; Periasamy, M.; Olson, E.N. Smooth muscle myosin heavy chain exclusively marks the smooth muscle lineage during mouse embryogenesis. Circ. Res. 1994, 75, 803-812. [CrossRef] [PubMed]

45. La Rovere, R.M.L.; Roest, G.; Bultynck, G.; Parys, J.B. Intracellular Ca(2+) signaling and Ca(2+) microdomains in the control of cell survival, apoptosis and autophagy. Cell Calcium 2016, 60, 74-87. [CrossRef] [PubMed]

46. Brini, M.; Bano, D.; Manni, S.; Rizzuto, R.; Carafoli, E. Effects of PMCA and SERCA pump overexpression on the kinetics of cell $\mathrm{Ca}(2+)$ signalling. EMBO J. 2000, 19, 4926-4935. [CrossRef] [PubMed]

47. Rizzuto, R.; Pinton, P.; Ferrari, D.; Chami, M.; Szabadkai, G.; Magalhães, P.J.; Di Virgilio, F.; Pozzan, T. Calcium and apoptosis: Facts and hypotheses. Oncogene 2003, 22, 8619-8627. [CrossRef] [PubMed]

48. Khananshvili, D. The SLC8 gene family of sodium-calcium exchangers (NCX)-Structure, function, and regulation in health and disease. Mol. Asp. Med. 2013, 34, 220-235. [CrossRef] [PubMed]

49. Nyhus, L.M.; Klein, M.S.; Rogers, F.B. Inguinal hernia. Curr. Probl. Surg. 1991, 28, 407-450. [CrossRef]

50. Brozovich, F.V.; Nicholson, C.J.; Degen, C.V.; Gao, Y.Z.; Aggarwal, M.; Morgan, K.G. Mechanisms of Vascular Smooth Muscle Contraction and the Basis for Pharmacologic Treatment of Smooth Muscle Disorders. Pharm. Rev. 2016, 68, 476-532. [CrossRef]

51. Knöll, R. Myosin binding protein C: Implications for signal-transduction. J. Muscle Res. Cell Motil. 2012, 33, 31-42. [CrossRef]

52. Ghahramani Seno, M.M.; Trollet, C.; Athanasopoulos, T.; Graham, I.R.; Hu, P.; Dickson, G. Transcriptomic analysis of dystrophin RNAi knockdown reveals a central role for dystrophin in muscle differentiation and contractile apparatus organization. BMC Genom. 2010, 11, 345. [CrossRef] 
53. Lin, B.; Govindan, S.; Lee, K.; Zhao, P.; Han, R.; Runte, K.E.; Craig, R.; Palmer, B.M.; Sadayappan, S. Cardiac Myosin Binding Protein-C Plays No Regulatory Role in Skeletal Muscle Structure and Function. PLoS ONE 2013, 8, e69671. [CrossRef]

54. Öztürk, F.; Tander, B.; Baysal, K.; Bernay, F. High association of congenital heart disease with indirect inguinal hernia. Pediatr. Cardiol. 2005, 26, 80-82. [CrossRef] [PubMed]

55. Kimura, A. Molecular genetics and pathogenesis of cardiomyopathy. J. Hum. Genet. 2016, 61, 41-50. [CrossRef] [PubMed]

56. Seidman, J.G.; Seidman, C. The genetic basis for cardiomyopathy: From mutation identification to mechanistic paradigms. Cell 2001, 104, 557-567. [CrossRef]

57. Hutson, J.M.; Hasthorpe, S. Testicular descent and cryptorchidism: The state of the art in 2004. J. Pediatr. Surg. 2005, 40, 297-302. [CrossRef]

58. Bendavid, R. The Unified Theory of hernia formation. Hernia 2004, 8, 171-176. [CrossRef]

59. Henriksen, N.A.; Yadete, D.H.; Sorensen, L.T.; Ågren, M.S.; Jorgensen, L.N. Connective tissue alteration in abdominal wall hernia. Br. J. Surg. 2011, 98, 210-219. [CrossRef]

60. Spivey, K.A.; Chung, I.; Banyard, J.; Adini, I.; Feldman, H.A.; Zetter, B.R. A role for collagen XXIII in cancer cell adhesion, anchorage-independence and metastasis. Oncogene 2012, 31, 2362-2372. [CrossRef]

61. Sato, K.; Yomogida, K.; Wada, T.; Yorihuzi, T.; Nishimune, Y.; Hosokawa, N.; Nagata, K. Type XXVI collagen, a new member of the collagen family, is specifically expressed in the testis and ovary. J. Biol. Chem. 2002, 277, 37678-37684. [CrossRef]

62. Becerril, C.; Pardo, A.; Montaño, M.; Ramos, C.; Ramírez, R.; Selman, M. Acidic fibroblast growth factor induces an antifibrogenic phenotype in human lung fibroblasts. Am. J. Respir. Cell Mol. Biol. 1999, 20, 1020-1027. [CrossRef]

63. Tanyel, F.C.; Müftüoglu, S.; Dagdeviren, A.; Kaymaz, F.F.; Büyükpamukçu, N. Myofibroblasts defined by electron microscopy suggest the dedifferentiation of smooth muscle within the sac walls associated with congenital inguinal hernia. BJU Int. 2001, 87, 251-255. [CrossRef]

64. Shimbori, C.; Bellaye, P.S.; Xia, J.; Gauldie, J.; Ask, K.; Ramos, C.; Becerril, C.; Pardo, A.; Selman, M.; Kolb, M. Fibroblast growth factor-1 attenuates TGF- $\beta 1$-induced lung fibrosis. J. Pathol. 2016, 240, 197-210. [CrossRef] [PubMed]

65. Chiego, D.J. Essentials of Oral Histology and Embryology; Intergovernmental Panel on Climate Change, Ed.; Cambridge University Press: Cambridge, UK, 2014; Volume 58, ISBN 9788578110796. 